\title{
RANCANG BANGUN AWAL MESIN LAS GTAW SEMI OTOMATIS UNTUK PENGELASAN PLAT BAJA
}

\author{
Alaya Fadllu Hadi Mukhammad ${ }^{1}$, Bambang Setyoko ${ }^{1}$, Murni ${ }^{1}$ \\ Muhammad Amiruddin ${ }^{2}$ Kevin Kusumo Abdillah ${ }^{3}$ Rizki Saputra Utama ${ }^{3}$
}

\begin{abstract}
ABSTRAK
Proses pengelasan GTAW banyak digunakan untuk industri makanan, pressure vessel, pesawat terbang maintenance dan manufaktur. Parameter-parameter pengelasan GTAW optimal merupakan salah satu faktor utama untuk menghasilkan lasan yang baik. Akan tetapi pada pengelasan manual Beberapa masalah yang timbul pada pengelasan adalah perbedaan tingkat keahlian operator las serta perubahan kondisi fisik dan psikis operator las. Tujuan utama rancang bangun ini adalah membuat desain, manufaktur mesin las GTAW semiotomatis dapat bekerja dengan baik. Ujicoba pengelasan kemudian dievaluasi menggunakan metode visual. Rancang bangun ini terdapat 3 sistem yaitu sistem pengelasan, Sistem Monitoring, Kontrol dan Penggerak Pengelasan GTAW, sistem feeder kawat las(Gambar 3.2). Rangka berupa meja ukuran 1x1 m dan terbuat dari profil hollow baja karbon rendah. Hasil pengujian mesin las dapat bekerja dengan baik. Hasil uji coba pengelasan menunjukkan bahwa
\end{abstract}

Kata Kunci: Rancang Bangun, GTAW, Semi Otomatis

PENDAHULUAN

Pengelasan GTAW seperti halnya GMAW dikembangkan dari tahun 1940 ketika Perang Dunia kedua dimulai. Pengembangan las GTAW bertujuan untuk membantu pengelasan pada material sulit seperti alumunium dan magnesium. Penggunaan GTAW sekarang telah berkembang untk penggunaan Stainless Steel dan Baja Kekuatan Tinggi (Jeyaprakash dkk, 2015)

Pengelasan GTAW (Gas Tungsten Arc Welding) mengacu terminologi penggunaan Tungsten sebagai elektroda dan Gas sebagai pelindung las dari Oksigen di atmosfer. Jika dalam kondisi pengelasan yang benar, Elektroda tungsten harusnya tidak meleleh (non consumable electrode). Untuk mencegah oksidasi Gas (Ar, He, or Ar-He mixture) biasanya disemburkan melalui torch. Pengelasan GTAW optimal pada pengelasan plat logam mencapai 0,25 inch. Walaiupun jenis pengelasan lain bayak yang lebih efisien dan murah, akan tetapi faktor

\footnotetext{
${ }^{1}$ Program Sarjana Terapan Rekayaya Perancangan Mekanik, Sekolah Vokasi, Universitas Diponegoro Semarang

${ }^{2}$ Fakultas Teknik, Jurusan Teknik Elektro, Universitas PGRI Semarang

${ }^{3}$ Mahasiswa Diploma III Teknik Mesin, Sekolah Vokasi, Universitas Diponegoro Semarang
} 
kebersihan, penampakan dan kemudahan dalam proses finishing menjadikan GTAW masih banyak digunakan (Jeyaprakash dkk, 2015).

Proses pengelasan GTAW banyak digunakan untuk industri makanan, pressure vessel, pesawat terbang maintenance dan manufaktur. Parameter-parameter pengelasan GTAW optimal merupakan salah satu faktor utama untuk menghasilkan lasan yang baik. Akan tetapi pada pengelasan manual Beberapa masalah yang timbul pada pengelasan adalah perbedaan tingkat keahlian operator las serta perubahan kondisi fisik dan psikis operator las, oleh karena itu rancang bangun ini bertujuan untuk memperbaiki kekurangan tersebut.

\section{METODE PENELITIAN}

Proses rancang bangun mesin Las GTAW Semi Otomatis terdiri dari 3 tahapan yaitu pembuatan desain, manufaktur dan uji coba pengelasan.

1. Pembuatan Desain (Perancangan)

Tahap permulaan dalam perancangan adalah menentukan kebutuhan (need) secara umum (Armanto dkk, 2012). Tujuan utama rancang bangun ini adalah pembuatan mesin las GTAW yang dapat menggantikan pekerjaan manusia secara pada pengelasan plat baja. Penggantian manusia dilakukan menggantikan gerakan tangan menjadi motor DC yang dihubungkan ke shaft berulir, sedangkan umpan kawat digantikan menggunakan mekanisme feeder pengelasan GMAW.

2. Manufaktur

Manufaktur dilakukan setelah proses perancangan selesai. Pada tahapan ini semua komponen mesin dirakit agar dapat berfungsi seperti yang direncanakan.

3. Uji coba pengelasan

Uji coba pengelasan dilakukan untuk mengetahui memastikan mesin bisa berfungsi dengan baikdengan pengelasan tanpa bahan tambah dan dengan bahan tambah.

\section{HASIL DAN PEMBAHASAN}

\section{Desain Mesin Las GTAW Autofeeder berbasis CNC}

Desain Mesin Las GTAW Semi Otomatis untuk Pengelasan Plat Baja menggunakan 3 sistem yaitu sistem pengelasan, Sistem Monitoring, Kontrol dan Penggerak Pengelasan GTAW, sistem feeder kawat las(Gambar 3.1 ). Rangka berupa meja ukuran 1x1 m dan terbuat dari profil hollow baja karbon rendah. Sistem penggerak menggunakan motor DC (ex motor Wiper HINO Lohan) sebanyak 1 buah yang dikontrol menggunakan sistem kontrol berbasis Arduino Uno R3 untuk menggerakkan ke arah X. Torch Sistem las GTAW berupa mesin las 
GTAW yang berfungsi untuk melebur kawat las, dan feeder kawat menggunakan sistem las GMAW yang telah dimodifikasi. Berikut komponen utama mesin las GTAW semi otomatis.

Tabel 1. Komponen mesin las GTAW Semi Otomatis

\begin{tabular}{|l|l|}
\hline 1. Flowmeter & 7. Mesin las GTAW \\
\hline 2. Tabung Gas Argon & 8. Feeder kawat las \\
\hline 3. Motor DC & 9. Tempat meletakkan benda kerja \\
\hline 4. Shaft penggerak X & 10. Torch \\
\hline 5. Shaft penggerak Y & 11. Rangka \\
\hline 6. Panel Power supply, potensio & 12. Area pengelasan \\
\hline
\end{tabular}

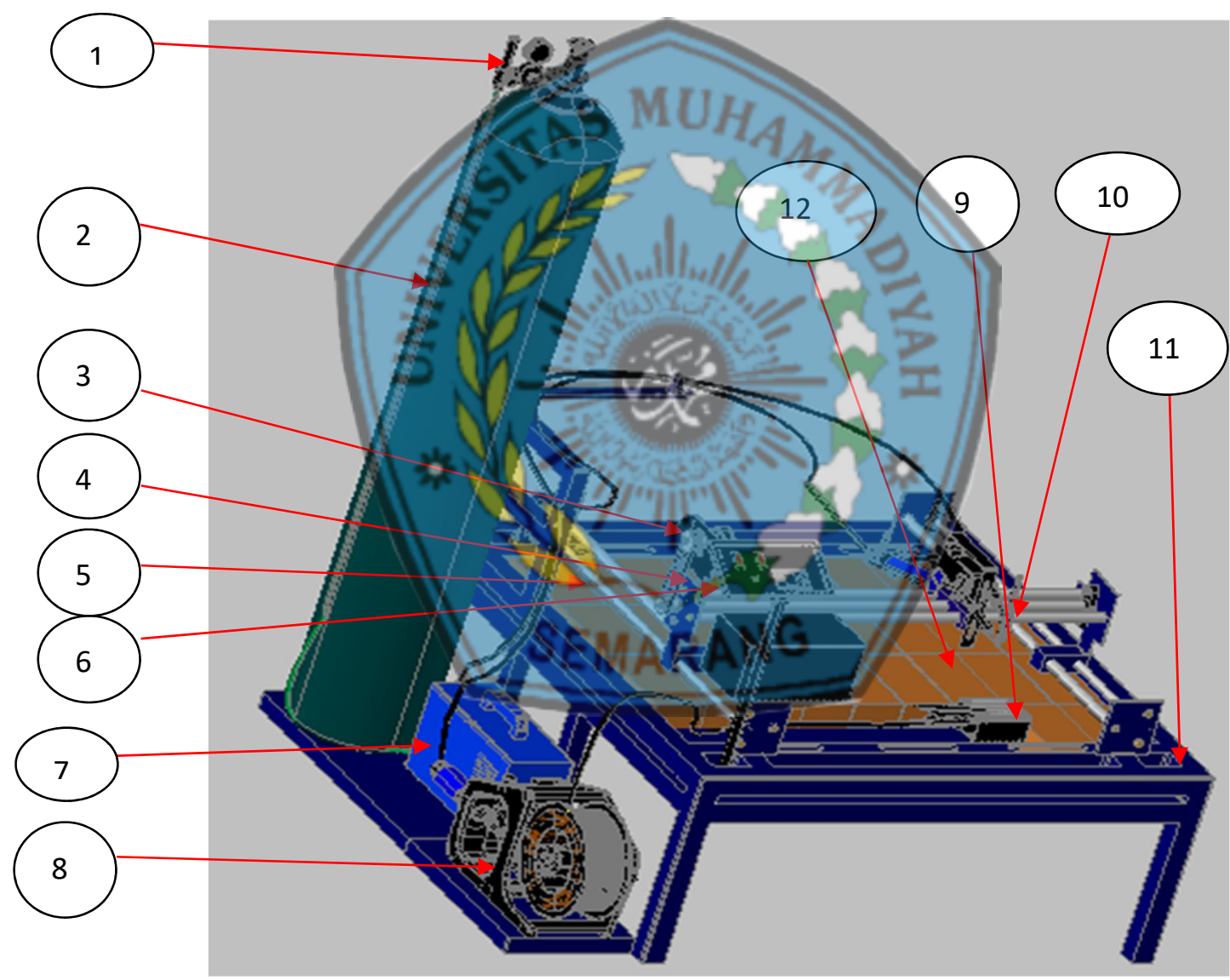

Gambar 1. Desain Mesin Las GTAW Semiotomatis

\section{Manufaktur}

\section{Sistem Pengelasan GTAW}

Trafo Las GTAW/MMA Inverter Lakoni Hawk 200E, merupakan mesin las yang dapat digunakan untuk mengelas stainless steel dengan menggunakan Tungsten Inert Gas arus Direct Current. Menggunakan Gas Argon untuk melindungi dari kontaminasi zat yang bisa 
mengganggu pengelasan. Selain itu mesin ini juga tetap dapat berfungsi untuk mengelas besi atau baja dengan metode MMA hingga 200 Ampere non-stop.

Mesin las ini menggunakan teknologi inverter dengan komponen daya MOSFET atau IGBT. Inverter merubah arus Alternating Current dari sumber tegangan menjadi direct current yang kemudian diperkuat menjadi $100 \mathrm{kHz}$. Hal ini menyebabkan ukuran transformer menjadi $30 \%$ lebih kecil.

Tabel 2 Spesifikasi Mesin Las GTAW

\begin{tabular}{|l|l|}
\hline Daya Listrik & 1500 Watt \\
\hline Arus Output & 10 - 200 Ampere (GTAW) \\
\hline Gas & Argon \\
\hline Efficiency & $85 \%$ \\
\hline Ketebalan Las & $0.3-10 \mathrm{~mm}$ \\
\hline Pendingin & Kipas \\
\hline Duty Cycle & $60 \%(200 \mathrm{~A}), 100 \%(160 \mathrm{~A})$ \\
\hline
\end{tabular}

Gambar 2 Mesin Las GTAW Lakoni

(https://www.tokopedia.com/jptretailindo/lakoni-hawk-200e-mesin-trafo-lastig-mma-inverter?) 


\section{Sistem Monitoring, Kontrol dan Penggerak Pengelasan GTAW}

Sistem penggerak terdiri atas 1 power supply, 2 motor DC, 1 driver motor DC Arduiuno R3

\section{- Power supply}

Penggunaan power supply ini adalah sebagai penyedia arus listrik DC yang dibutuhkan Motor $D C$ untuk agar bisa bergerak dan dikombinasikan dengan relay dan saklar sehingga motor $D C$ bisa bergerak maju dan mundur. Kriteria yang dicapai adalah sebagai berikut:

$>$ Kuat arus yang digunakan : $5 \mathrm{~A}$

$>$ Tegangan yang digunakan $: 12 \mathrm{~V}$

\section{- Motor DC dan bracket}

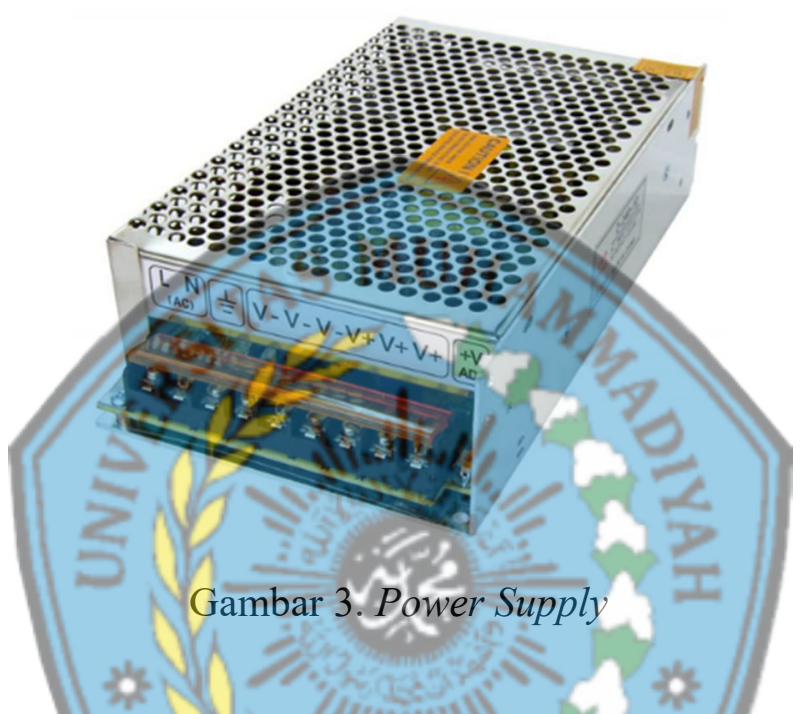

Motor DC yang digunakan dalam rancang bangun ini/adalah Motor DC komersial penggerak wiper mobil HINO Lohan. Motor DC yang berfungsi sebagai penggerak shaft pada las sehingga mesin bisa berputar dan megikuti alur pengelasan. Bracket adalah dudukan yang digunakan motor wiper yang berfungsi juga untuk dudukan pulley sehingga mesin bisa berputar dengan baik.
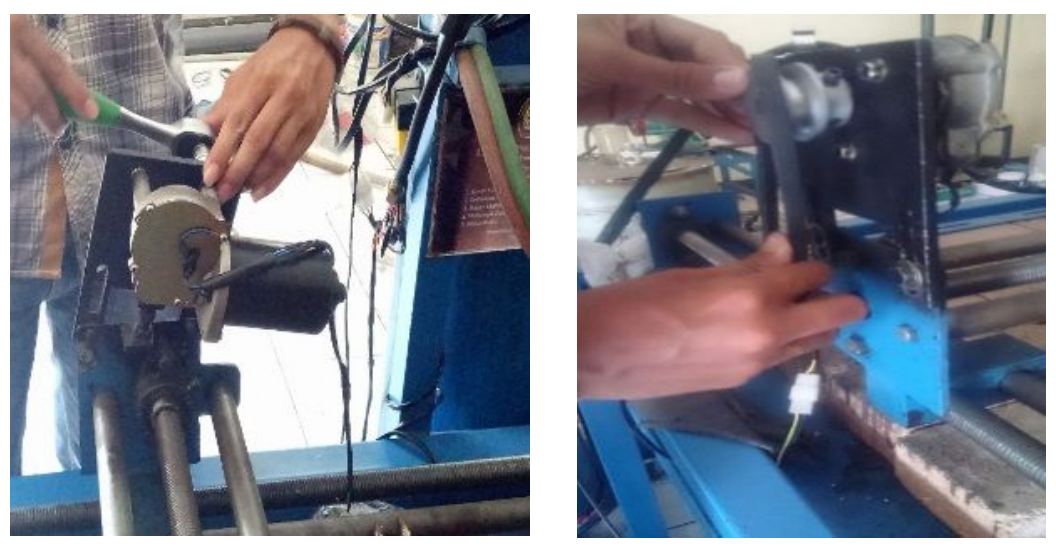

Gambar 3.4 Motor DC dan bracket 


\section{- Motor DC driver}

Driver Motor DC berfungsi untuk menggerakkan Motor DC dimana perubahan arah Motor DC tersebut bergantung dari nilai tegangan yang diinputkan pada input dari driver itu sendiri dan kecepatan Motor DC.

Driver Motor DC yang digunakan adalah Embedded Module Series (EMS) $30 \mathrm{~A} \mathrm{H}$ Bridge. Embedded Module Series (EMS) 30 A H-Bridge merupakan driver H-Bridge yang didisain untuk menghasilkan drive 2 arah dengan arus kontinyu sampai dengan 30 A pada tegangan 5,5 Volt sampai 16 Volt. Modul ini dilengkapi dengan rangkaian sensor arus beban yang dapat digunakan sebagai umpan balik ke pengendali. Modul ini mampu men-drive bebanbeban induktif seperti misalnya relay, solenoid, motor DC,motor stepper, dan berbagai macam beban lainnya.

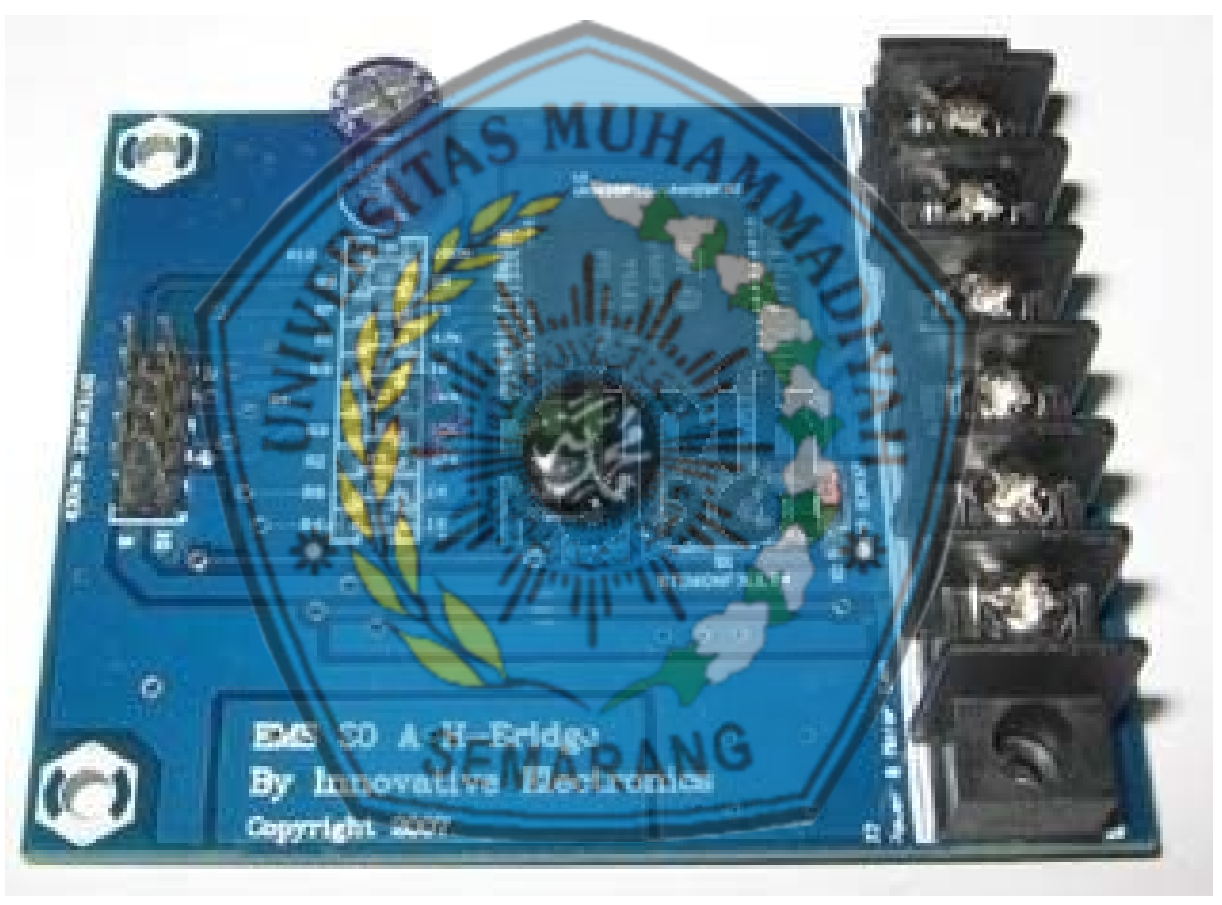

Gambar 5. Driver Motor Embedded Module Series (EMS) 30 A H-Bridge

\section{- Arduino R3}

Arduino Uno R3 adalah papan pengembangan (development board) mikrokontroler yang berbasis chip ATmega328. Disebut sebagai papan pengembangan karena board ini memang berfungsi sebagai arena prototiping sirkuit mikrokontroler. Dengan menggunakan papan pengembangan, pengguna lebih mudah merangkai rangkaian elektronika mikrokontroler dibanding jika memulai merakit ATMega328 dari awal di breadboard. Arduino Uno memiliki 14 digital pin input / output (atau biasa ditulis I/O, dimana 6 pin diantaranya 
dapat digunakan sebagai output PWM), 6 pin input analog, menggunakan, koneksi USB, jack listrik, header ICSP dan tombol reset (Novain, 2018)

Pemrograman board Arduino dilakukan dengan menggunakan Arduino Software (IDE). Chip ATmega328 yang terdapat pada Arduino Uno R3 telah diisi program awal yang sering disebut bootloader. Bootloader tersebut yang bertugas untuk memudahkan melakukan pemrograman lebih sederhana menggunakan Arduino Software, tanpa harus menggunakan tambahan hardware lain. Cukup hubungkan Arduino dengan kabel USB ke PC atau Mac/Linux , jalankan software Arduino Software (IDE), dan sudah bisa mulai memrogram chip ATmega328.

\title{
Spesifikasi Ardunio Uno R3:
}

Chip Mikrokontroller

Tegangan Operasi

Tegangan Input

Digital I/O pin

\author{
oller
}

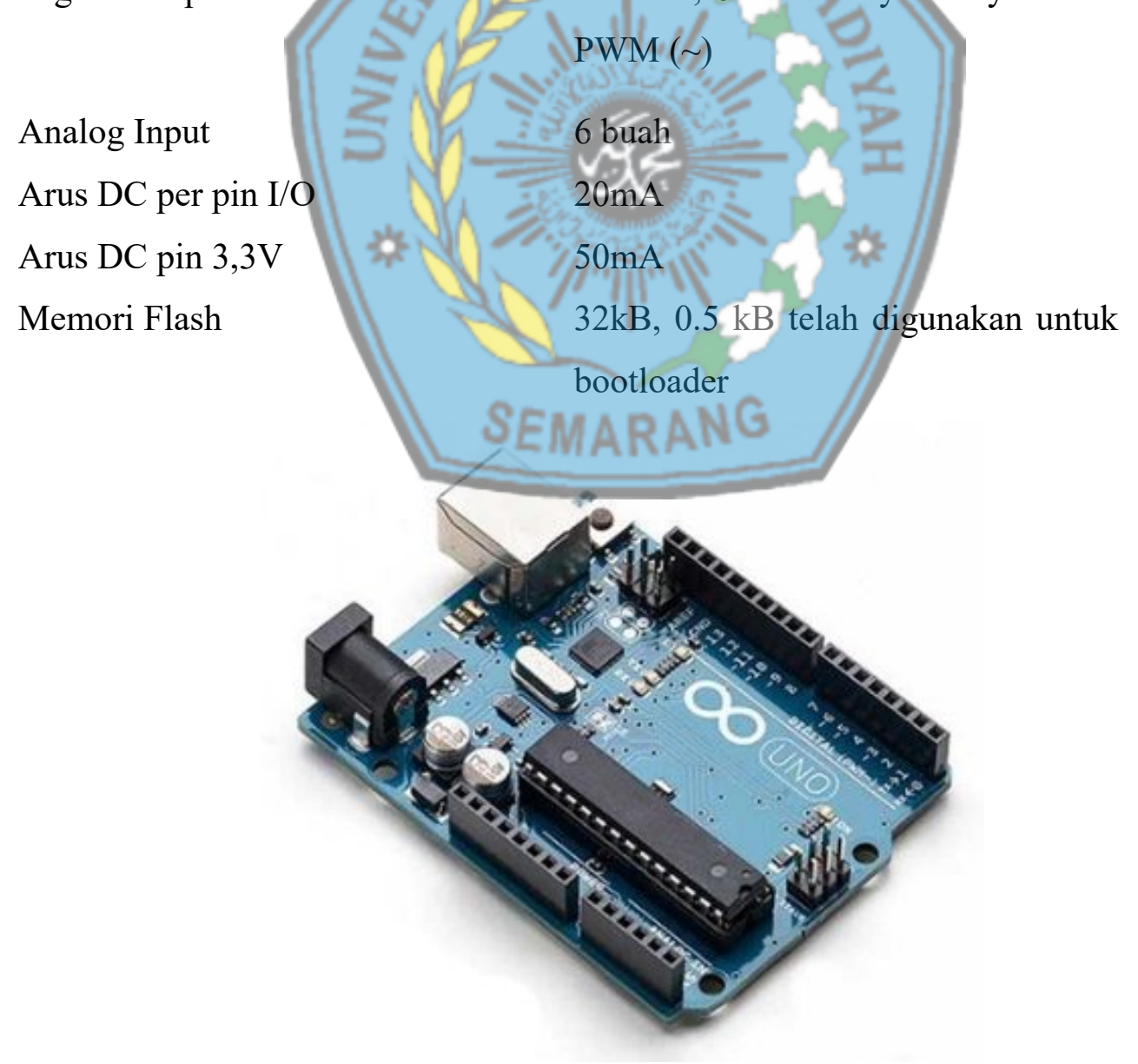

Gambar 6 Arduino Uno R3 
- Pulley dan Belt

Puley dan belt berfungsi untuk mentransmisikan daya dari motor DC menunju shaft berulir. Hasil perhitungan dan ketersediaan di pasar komersial maka pulley yang digunakan adalah diameter 39 dan $50 \mathrm{~mm}$ dengan posisi penempatan akselerasi (dipercepat) dan belt yang digunakan adalah yang digunakan adalah tipe A dengan jarak pusat puley adalah 187,55 mm

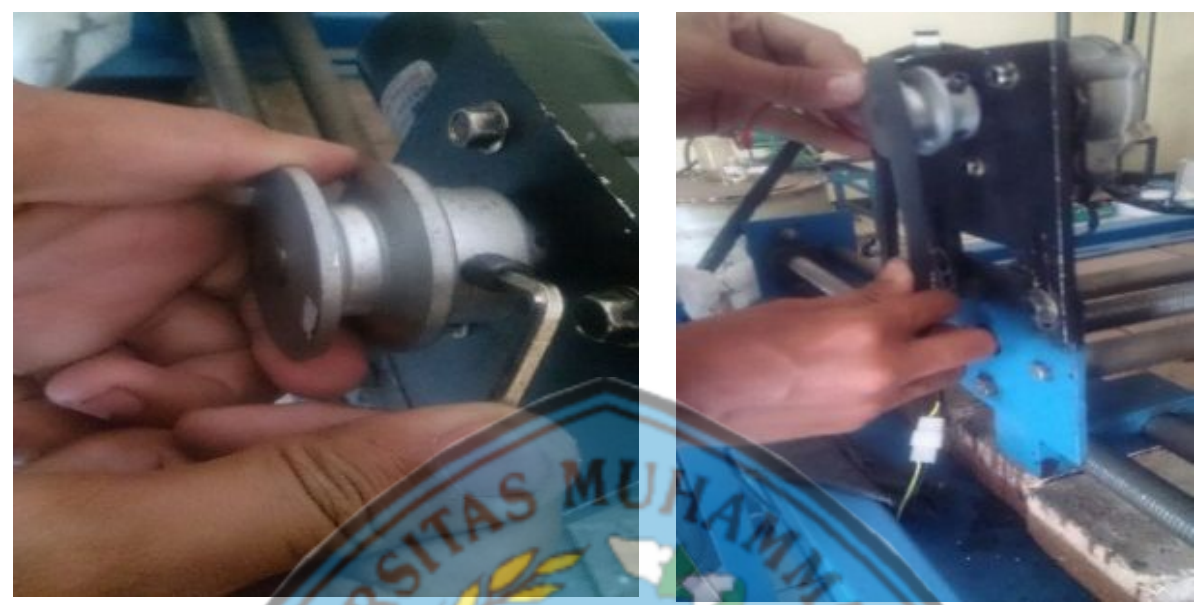

- Shaft berulir

Gambar 7. Pemasangan pulley dan belt

Shaft berulir digunakan untukmenggerakkan torch GTAW dan feeder. Shaft berulir yang digunakan berjumlah 3 dengan ukuran ulir withworth $8 \mathrm{G}$ 1inch.

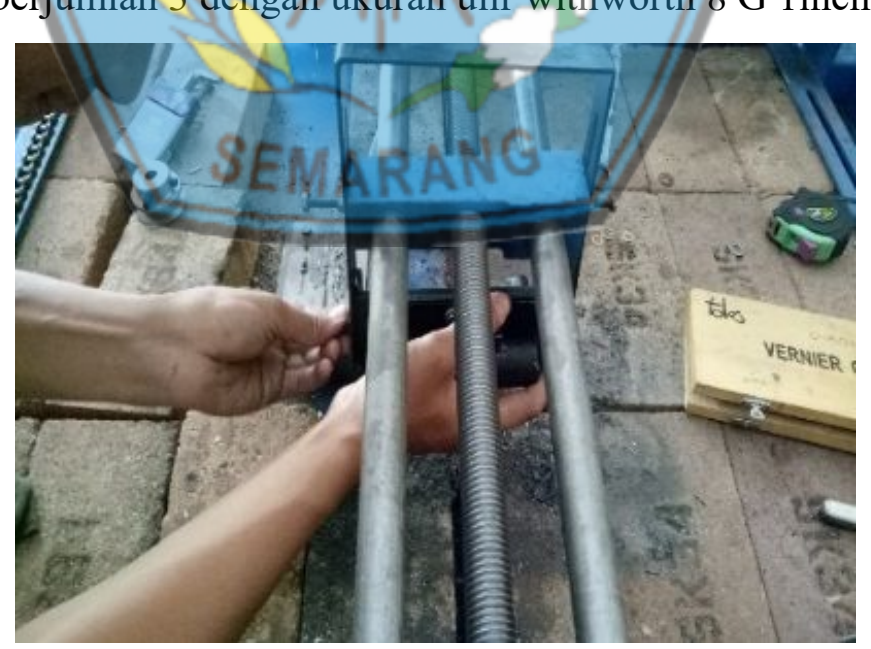

Gambar 8. Pemasangan pulley dan belt

\section{- Feeder Kawat Las}

Feeder merupakan sebuah alat dalam rangkaian pengelasan yang berfungsi untuk mengumpankan kawat las. Feeder terdiri dari beberapa bagian utama, antara lain: 


\section{a. Motor}

Motor digunakan untuk memutar roller feeder yang mengumpankan kawat torch. Motor ini digerakkan menggunakan power supply direct current $24 \mathrm{v} 5 \mathrm{~A}$.

b. Gulungan Kawat

Gulungan kawat $15 \mathrm{Kg}$ dengan spesifikasi AWS A5.18-05 : ER70S-6 dengan diameter 1 mm. Kode AWS A5.18-05 : ER70S-6 memiliki arti sebagai berikut (https://www.pengelasan.net/kode-kawat-las/):

$$
\begin{array}{ll}
\text { AWS } & =\text { American Welding Standart } \\
\text { A5.18-05 } & =\text { elektroda low alloy steel } \\
\text { E } & =\text { Elektroda } \\
\text { R } & =\text { Rod (Dapat digunakan untuk GMAW, tanpa flux) } \\
70 & =\text { minimum Tensile Strength 70 KSI } \\
\text { S } & =\text { Elektroda construction Solid } \\
6 & =\text { Chemical composition carbon steel }
\end{array}
$$

c. Roller

Roller berfungsi untuk mengumpankan kawat dari gulungan kawat disebelah kanan (dari gambar) menuju torch. Terdapat 2 roller yang menjepit kawat dengan roller bawah terhubung dengan motor,sedangkan roller atas yang dijepit olehtuas penjepit. Kawat dari gulungan sebelah kanan diarahkan menuju roller ke selang dan torch untuk diarahkan ke mesin las.

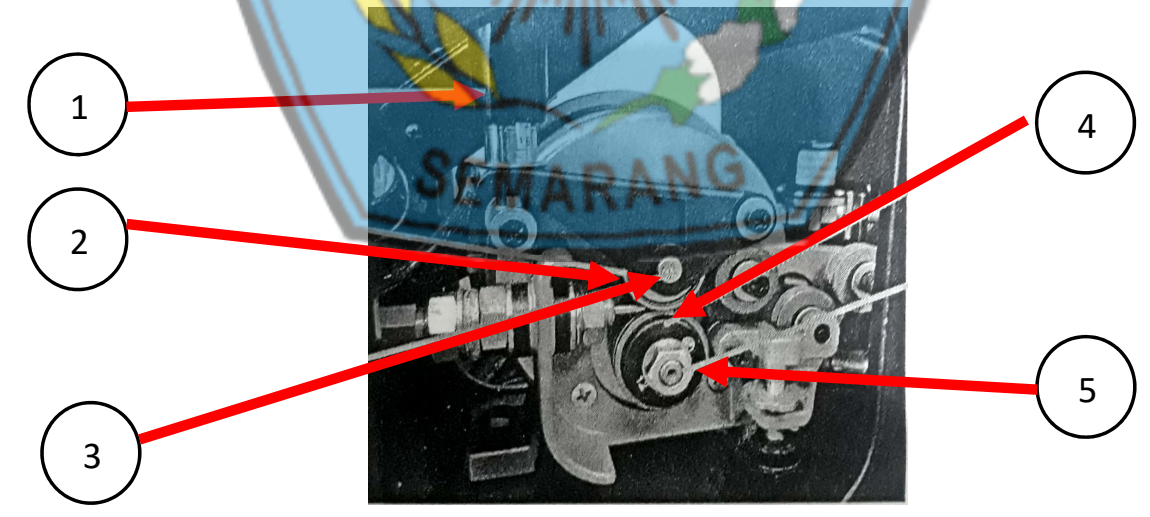

Keterangan :

1. Tuas pengunci roller

2. Roller Atas

3. Baut pengunci roller atas

4. Roller bawah

5. Shaft yang terhubung dengan motor

Gambar 9. Mekanisme Roller Feeder 


\section{- Panel Kontrol}

Panel kontrol berfungsi sebagai tempat dari beberapa komponen yaitu, Digital Control Power supply Direct Current 5 A, dan beberapa saklar untuk mengatur feeding wire, gerak torch las serta pengaturan arahnya. Panel kontrol terbuat dari bahan akrilik bening yang memiliki ketebalan $3 \mathrm{~mm}$.

\section{- Digital Control Power supply Direct Current 5 A}

Digital Control Power supply Direct Current 5 A berfungsi untuk mengatur tegangan dari power supply direct current ke motor feeder dan mengatur kecepatan linier dari motor wiper.

\section{- Power Supply}

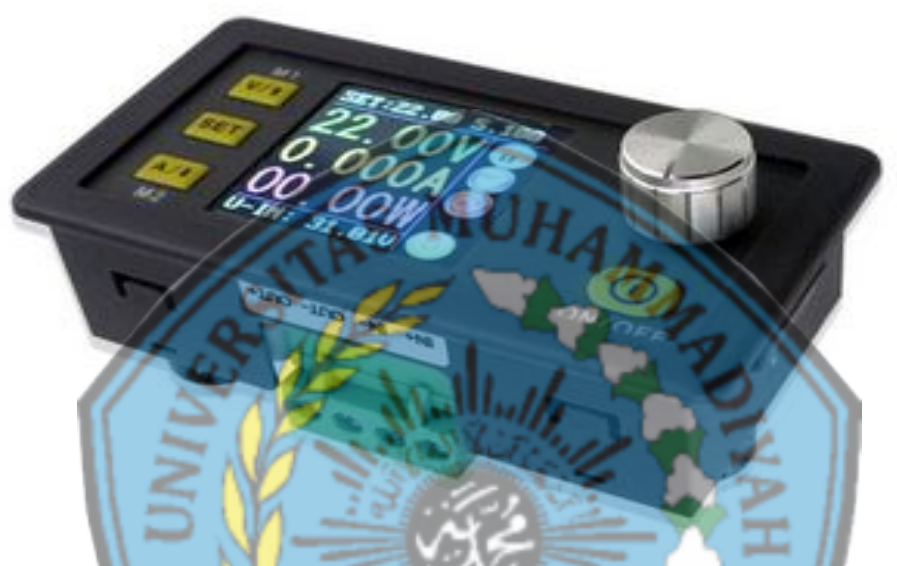

Gambar 10 Digital Control Power Supply Direct Current 5 A

Power supply berfungsi untuk memberikan daya listrik untuk motor penggerak feeder. Spesifikasi power supply di feeder kawat las $24 \mathrm{~V}, 5 \mathrm{~A}$.

- Flasher

Flasher berfungsi untuk memutus dan menghubungkan arus listrik secara otomatis dengan kemampuan 60-200 kedipan tiap menit. Flasher dalam penggunaan las berfungsi untuk mengatur kecepatan keluar dari bahan tambah. 


\section{HASIL PERAKITAN}

Semua komponen yang ada kemudian dirakit dan dihubungkan dengan sistem kontrol yang telah dibuat. Gambar 3.11.menunjukkan Mesin Las GTAW yang siap untuk diuji coba pengelasan

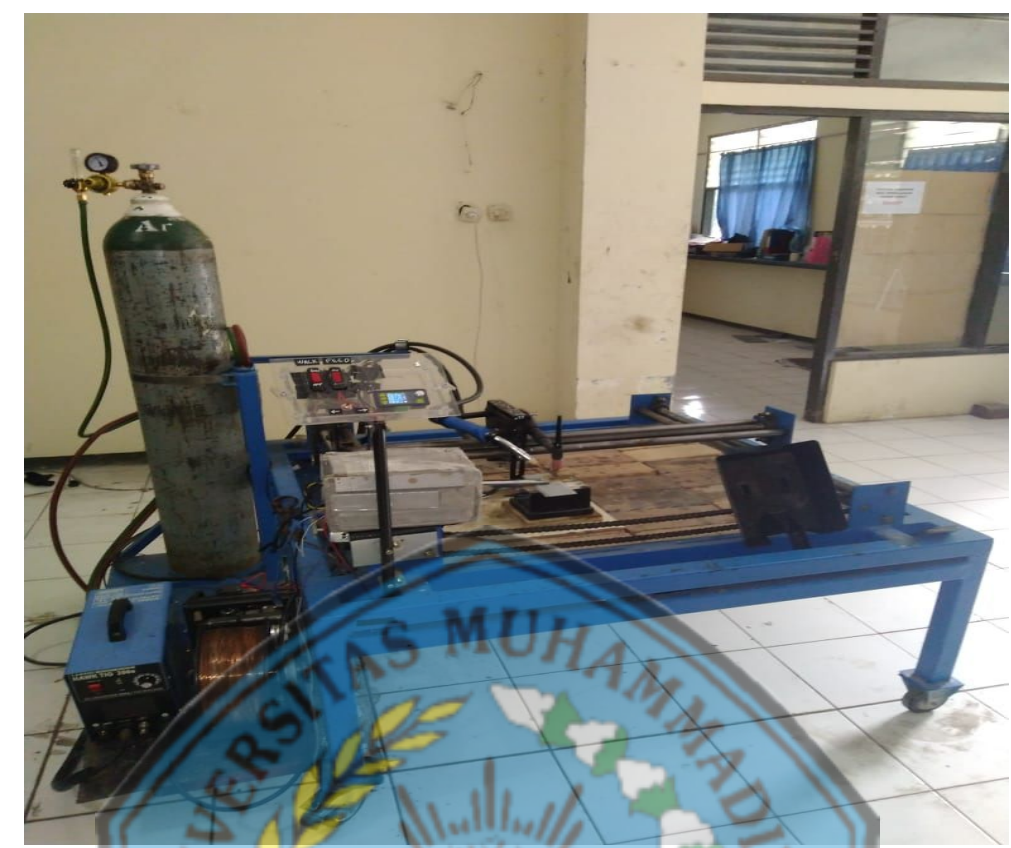

Gambar 11. Mesin las GTAW semiotomatis yang telah dirakit

\section{UJI COBA PENGELASAN}

Uji coba pengelasan dilakukan dengan pada plat baja komersial dengan ukuran 120x40x1,5 mm sebanyak dua buah kemudian dilakukan pengelasan dengan kawat feeder spesifikasi AWS A5.18-05 : ER70S-6 diameter 1 mm parameter seperti pada Tabel 3.

Tabel 3. Parameter Pengelasan

\begin{tabular}{|c|c|c|c|c|c|c|}
\hline No. & Variasi & $\begin{array}{c}\text { Tebal Plat } \\
(\mathrm{mm})\end{array}$ & $\begin{array}{c}\text { Kecepatan } \\
\text { linier } \\
(\mathrm{mm} / \mathrm{s})\end{array}$ & $\begin{array}{c}\text { Kuat Arus } \\
(\text { Ampere })\end{array}$ & $\begin{array}{c}\text { Jarak } \\
\text { Tungsten } \\
(\mathrm{mm})\end{array}$ & $\begin{array}{c}\text { Kecepatan } \\
\text { Feeder } \\
(\mathrm{mm} / \mathrm{s})\end{array}$ \\
\hline 1. & 1 & 1,5 & 0,5 & 60 & 0,5 & 2 \\
\hline
\end{tabular}

Pada pengujian pengelasan plat dengan ketebalan 1,5 mm dengan variasi jarak tungsten, pada jarak tungsten $0,5 \mathrm{~mm}$, kuat arus $60 \mathrm{~A}$, kecepatan pengelasan $0,5 \mathrm{~mm} / \mathrm{s}$, dan putaran flasher $160^{\circ}$ dihasilkan hasil lasan yang baik karena nyala api yang stabil dan tidak timbul percikan api saat proses pengelasan. 


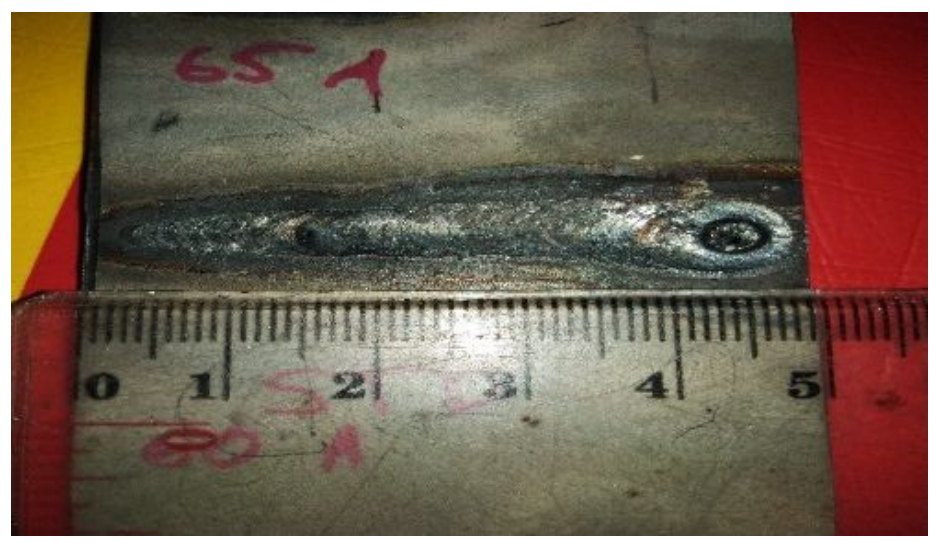

Gambar 12. Hasil Pengelasan pada variasi 1

\section{KESIMPULAN}

1. Mesin las GTAW semiotomatis dapat bekerja dengan baik

2. Hasil pengelasan pengelasan plat $1,5 \mathrm{~mm}$ menunjukkan lasan yang reltif baik.

SARAN

Mesin las yang dihasilkan masih gerakan satu sumbu yaitu $\mathrm{X}$, ke depannya bisa dikembangkan ke arah Y dengan kontrol PMC.

\section{UCAPAN TERIMA KASIH}

Tim penulis mengucapkan terimakasih kepada Kementerian Riset, Teknologi dan Pendidikan Tinggi atas pendanaan penelitian ini melalui skema Riset Pengembangan dan Penerapan sumber dana selain APBN TA 2018 Universitas Diponegoro Semarang.

\section{DAFTAR PUSTAKA}

Armanto, Eko. Aan Burhanudin, Didi, D.K.Dian Prabowo, Ismoyo, Jamari. 2012. Perancangan Mesin Uji Tribologi Pin on Disc. Prosiding SNST ke-3, Fakultas Teknik Universitas Wahid Hasyim Semarang

Jeyaprakash, N. Adisu, Haile., Arunprasath, M.2015. The Parameters and Equipments Used in TIG Welding: A Review. The International Journal Of Engineering And Science (IJES).

Novain, Nanda. 2018. Rancang Bangun Sistem Pengaman Garasi Rumah Dengan Kendali Jarak Jauh Menggunakan Teknologi Bluetooth Berbasis Arduino. Proyek Akhir, STIMIK AKAKOM Yogyakarta

https://www.pengelasan.net/kode-kawat-las/ diakses 11 September 2018. 
https://www.tokopedia.com/jptretailindo/lakoni-hawk-200e-mesin-trafo-las-tig-mmainverter?ev_efid=Cj0KCQiAurjgBRCqARIsAD09sg8GXAIo5im83uh8qvGA31vFD5St TtmDSxP5EWoSJdIqms8OSn62h3caAjOHEALw_wcB:G:s\&gclid=Cj0KCQiAurjgBR CqARIsAD09sg8GXAIo5im83uh8qvGA3lvFD5StTtmDSxP5EWoSJdIqms8OSn62h3c aAjOHEALw_wcB\&gclsrc=aw.ds\&ef_id=V0SJbwAABOzy94-p:20181210084729:s diakses 10 November 2018

PENULIS:

\section{ALAYA FADLLU HADI MUKHAMMAD}

Program Sarjana Terapan Rekayaya Perancangan Mekanik, Sekolah Vokasi, Universitas Diponegoro Semarang

J1.Prof. H. Sudharto, SH - Tembalang, Semarang.Email : alayad3tm@gmail.com

\section{BAMBANG SETYOKO}

Program Sarjana Terapan Rekayaya Perancangan Mekanik, Sekolah Vokasi, Universitas Diponegoro Semarang

\section{MURNI}

Program Sarjana Terapan Rekayaya Perancangan Mekanik, Sekolah Vokasi, Universitas Diponegoro Semarang

\section{MUHAMMAD AMIRUDDIN}

Fakultas Teknik, Jurusan Teknik Elektro, Universitas PGRI Semarang.

\section{KEVIN KUSUMO ABDILLAH}

Mahasiswa Diploma III Teknik Mesin, Sekolah Vokasi, Universitas Diponegoro Semarang Jl.Prof. H. Sudharto, SH - Tembalang, Semarang

\section{RIZKI SAPUTRA UTAMA}

Mahasiswa Diploma III Teknik Mesin, Sekolah Vokasi, Universitas Diponegoro Semarang Jl.Prof. H. Sudharto, SH - Tembalang, Semarang. 